\title{
Seven rules for researchers to increase their impact on the policy process
}

\author{
E. Mostert and G. T. Raadgever \\ Delft University of Technology, Stevinweg 1, 2628 CN Delft, The Netherlands \\ Received: 12 February 2008 - Published in Hydrol. Earth Syst. Sci. Discuss.: 25 March 2008 \\ Revised: 12 June 2008 - Accepted: 16 July 2008 - Published: 11 August 2008
}

\begin{abstract}
This paper addresses the question of how hydrologists and other researchers can contribute most to water management practice. It reviews the literature in the field of science and technology studies and research utilization and presents the results in the form of seven "rules" for researchers. These are (1) Reflect on the nature and possible roles of science and expertise; (2) Analyze the stakeholders and issues at stake; (3) Choose whom and what to serve; (4) Decide on your strategy; (5) Design the process to implement your strategy; (6) Communicate!; and (7) Consider your possibilities and limitations. A key notion in this paper is that research always involves selection and interpretation and that the selection and interpretations made in a specific case always reflect the values and preferences of those involved. Collaboration between researchers and the other stakeholders can increase the legitimacy and utilization of the research and can prevent the researchers' specific expertise from being lost.
\end{abstract}

\section{Introduction}

Science and policy often seem to be two different worlds (Caplan, 1979; Bourdieu, 2001; Borrowski and Hare, 2007). Whereas science aims to produce universally valid knowledge, policy is about practical action to address specific issues. Moreover, whereas science requires mastery of scientific skills and knowledge of the scientific literature, policy requires managerial and political skills. The major rewards are either recognition by the peers, or popularity and votes.

Yet, in practice science and policy influence each other in many different ways (Beck, 1992; Buuren and Edelenbos, 2004). Science can only exist as an autonomous

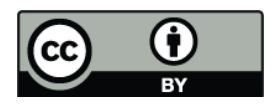

Correspondence to: E. Mostert (e.mostert@tudelft.nl) "social field" with its own rules if it enjoys social and political support. The more autonomous it is, the more support it needs and the more it reflects the social and political structure (Bourdieu, 2001). In addition, policy can influence science more directly, for instance by funding research on a limited number of topics only. Researchers, in turn, can influence policy by putting new issues on the agenda and developing solutions for old ones.

This paper addresses the question how researchers can contribute most to the policy process. It deals specifically with hydrological research and water management, but most issues addressed in this paper are also relevant for other types of research and other forms of natural resources management. The paper is structured according to seven "rules" that researchers should consider in order to contribute more effectively to the policy process. These rules are based primarily on a review of the literature in the field of science and technology studies and research use, as well as on personal involvement in a number of water-related research projects, such as the SQR project (Lorenz, 1999; and Veeren, 2002) and the ongoing Niederrhein case study, a joint activity of the NeWater project (www.newater.info) and the ACER project (www.adaptation.nl; Raadgever et al., 2008). The seven rules are not meant to prescribe the law to researchers or provide them with a recipe for success, but to stimulate reflection on their role in the policy process. The final section gives suggestions for further research.

\section{Reflect on the nature and possible roles of science and expertise}

The first rule is to reflect on the nature of science and expertise and the different roles that they can play in the policy process (see for instance Pinch and Bijker, 1984; Collingridge and Reeve, 1986; Latour, 1987; Feyerabend, 1988; Beck, 1992; Bourdieu, 2001). One of the first authors writing about

Published by Copernicus Publications on behalf of the European Geosciences Union. 
these subjects was the Greek philosopher Plato. In his work "The Republic", Plato distinguishes between the world of the ever-changing objects and illusions and the ulterior reality of the unchanging Forms or Ideas. The latter constitute the essential structure of nature and are only accessible for "philosophers" with many years of formal training. Since ruling a just society would require knowledge of the Forms, it follows that philosophers should become rulers or rulers philosophers (Plato and Lee, 1974).

The direct descendants of Plato's philosophers are today's scientists and technical experts. They are often seen as having privileged access to the truth because of their formal training, and while few would argue that experts should rule society, many think that they can and should provide a certain and objective basis for this (e.g. Jasanoff, 2003; Irwin, 2006). Yet, these views have not remained unchallenged. Since the 1970s, numerous studies have been conducted on laboratory life, scientific and technical controversies and technological decision-making. These studies have shown that science is less objective and certain than is often thought, that the practice of science is much more messy than is suggested by the published accounts of science, and that the "facts" do not decide scientific controversies, but rather that the resolution of controversies determines what is accepted as facts.

Researchers have to make many choices concerning, for instance, the thematic, geographic and temporal delimitation of their research, the alternatives to include or exclude, and how to deal with uncertainty (cf. Frankena, 1988). These choices are influenced by the wishes and requirements of the funding agencies (no research without funding) and by the world view and values of the researchers involved (e.g. Thompson et al., 1990; Douglas, 2005). In addition, the disciplinary background of the researchers plays a key role. Ecologists, for instance, are likely to focus on different issues and aspects and come up with different solutions than hydrologists or economists (cf. framing theory: Dewulf et al., 2005a, 2005b; cf. Box 1).

A key issue in science is who counts as an expert and can be relied upon, and who does not. In his seminal 1983 paper, Thomas Gieryn examined this issue as a practical problem for the experts. Experts would compare their expertise and thereby themselves favourably to "pseudo" and "non-experts" by defining themselves in terms of their formal training and their alleged objectivity. In this way, they acquire authority and influence, protect themselves from political interference, and exclude the pseudo and non-experts (Gieryn, 1983).

Based on analyses such as these, many authors have concluded that science and expertise are socially constructed and reflect primarily social realities. Yet, we may argue that science and expertise should reflect material realities as well. We may still assume that there is an external material world, but this world is not directly accessible and can be studied and interpreted in many different ways. How it is studied and interpreted in practice is shaped by social factors.
Nonetheless, to quote Knorr Cetina (1995, p. 148), the material world "offers resistances (...). Facts are not made by pronouncing them to be facts but by being intricately constructed against the resistances of the natural (and social!) order."

In a similar vein, we may argue that there should be something "real" behind the qualification as an expert: the possession of specific skills and information (cf. Collins and Evans, 2002). A major issue is how to recognize the relevant expertise and experts in a specific case (Rip, 2003). To simplify matters, we can distinguish between "certified experts" with formal qualifications, usually within a specific discipline, and "lay experts", who lack formal qualifications but still possess relevant skills and information. A major issue with respect to certified experts is the identification of the relevant disciplines for the issue at stake. Is, for instance, flood risk management only a topic for engineers or also for ecologists, economists, political scientists, sociologists, lawyers, etc.? In practice, many experts compare their own discipline favourably to other disciplines and define their own as more fundamental, difficult, scientific or relevant, thereby excluding or subordinating the other disciplines (cf. Gieryn, 1983). Other experts, however, are more open to other disciplines.

The identification of the relevant lay experts is even more difficult. Lay experts do not only lack formal qualifications, but also the social status that goes with these qualifications. In theory, lay expertise and "certified expertise" can complement each other, but in practice lay expertise is often not recognized and certified experts sometimes seem to be personally challenged by the notion that lay persons can possess relevant expertise as well (see for instance Wynne, 1992; Scheer, 1996; Petts and Brooks, 2006).

Collins and Evans (2002) have called for a normative theory of expertise that can be used to improve the contribution of (certified) experts to technological decision-making. Such a theory should avoid the false choice between technocracy and participation (Jasanoff, 1990). Whereas technocracy denies the role of values in science and technology and gives an undue influence to the experts and their financers, the participation option relies exclusively on involving the other stakeholders and improving interest representation and denies them the benefit of the experts' skills and knowledge. Instead, we could liken expertise to maps. Many different maps can be made of a given area, each selecting and representing different features and serving different purposes, but to serve their purpose, each map should be correct and contain no mistakes. Similarly, any topic can be studied in many different ways, each reflecting different values and worldviews, but this does not make any opinion as good as another. The scientific standards of validity and reproducibility are still relevant, but they should be complemented with others (cf. the concept of "extended peer review": Funtowicz and Ravetz, 1990).

Finally, modern science and technology are not the only ways to make sense of and cope with the world. In addition, 
In their article "Water footprints of nations" Hoekstra and Chapagain (2007) discuss the "water footprint" of the different countries of the world and the means to reduce the footprint. The water footprint is defined as the total freshwater volume that is used to produce the goods and services consumed by the population of that country. Contrary to traditional water use indicators, the water footprint includes the "virtual water” (Allan, 2003) that is embedded in the goods and services that are imported or exported. Using some simplifying assumptions, the authors calculate the global average water footprint to be $1240 \mathrm{~m}^{3} / \mathrm{cap} / \mathrm{yr}$, ranging from a mere $700 \mathrm{~m}^{3} / \mathrm{cap} / \mathrm{yr}$ for China to $2480 \mathrm{~m}^{3} / \mathrm{cap} / \mathrm{yr}$ for the USA. The means to reduce the water footprint discussed in the paper are 1) more water efficient production methods, 2) changes in consumption patterns (e.g. less meat), and 3) moving production to regions where water efficiency is higher.

The article illustrates that research incorporates many (extra-scientific) choices and that these choices are influenced by the background of the researchers. To start with the last point, the article is mostly limited to technical water management issues, and as such reflects the disciplinary background of its authors. The basic concept used - water footprint - frames the water scarcity issue in a specific way, implicitly suggesting virtual water trade as a possible solution (see also the third measure to reduce the water footprint). There is no discussion of the economic and political aspects of virtual water trade. Virtual water trade is for instance not a solution for poor farmers without alternative sources of income and who cannot buy imported food. Moreover, the official policy of some countries is to be self-sufficient in food supply and minimize food imports in order to reduce dependence on other countries, to promote national agriculture or to support their water claims in an international dispute (e.g. Wichelns, 2001). (The authors briefly mention some of these issues elsewhere: Hoekstra and Chapagain, 2008.) Finally, since the water footprint is expressed in per capita figures in the article, the effect of population size on water use is overlooked (e.g. Pimentel et al., 1994). Population policy as a possible water management measure is not discarded, but simply not mentioned at all.

Box 1. Analyzing the article "Water footprints of nations: Water use by people as a function of their consumption patterns" (Hoekstra and Chapagain, 2007).

there are traditional knowledge systems that reflect different social realities and different values (Watson-Verran and Turnbull, 1995). We are not proposing that researchers abandon modern science and technology, but that they recognize the inherent values and acknowledge the achievements of traditional knowledge systems.

\section{Analyze the stakeholders and issues at stake}

In order to contribute to the policy process, it is important to know who the stakeholders in this process are. A stakeholder can be defined as any organisation, group or individual who can influence or may be affected by a problem or its solution (cf. Freeman, 1984). Consequently, there are two categories of stakeholders: the "influential stakeholders" and the "affected stakeholders". The views and interests of the influential stakeholders need to be taken into account because they are the major players in the policy process and can block or promote change. The affected stakeholders may need to be involved for ethical or democratic reasons. In practice, the two categories often overlap (Mostert, 2003).

A stakeholder analysis often starts with a specific problem or issue identified by one or a few stakeholders, usually 
the funding agency. Next, the stakeholders for this issue are identified. This requires that the resources and the perceptions and interests of the different stakeholders are inventoried. The resources include their legal competencies, political influence, financial means and expertise, and determine how much weight a stakeholder carries in the policy process and what he or she can contribute. The stakeholders' perceptions and interests determine what they see as an issue and as potential solutions. Researchers do not have to accept these perceptions and interests uncritically, but they should address them if they want their research to be relevant for the stakeholders. Moreover, it may be necessary to redefine and broaden the initial problem in order to ensure relevance (see for instance Gray, 1989). A final issue that can be addressed in a stakeholder analysis are the relations between the different stakeholders. Knowledge of these relations helps to assess the influence of individual stakeholders and moreover, provides valuable information if collaboration with groups of stakeholders is foreseen.

Different methods can be used for analyzing the stakeholders, such as network analysis, discourse analysis and cognitive mapping (Hermans, 2005). In addition, more informal approaches can be used that require less time and expertise (Ridder et al., 2005). These may include a small meeting with an initial group of stakeholders to identify missing stakeholders. Such a meeting can stimulate the stakeholders to explore mutual interdependencies, which form a good basis for collaboration with each other (Gray, 1989; Mostert et al., 2008), and can initiate close collaboration between the stakeholders and the researchers.

It is not always necessary that the water experts themselves conduct a stakeholder analysis: they may also use analyses made by others. Yet, water experts may not even use analyses that have been made specifically for them. Reasons for this include the tendency of many (water) experts to stick to their own interpretation of the issues at stake and to their technical tools and approaches. This can reduce the relevance of their work to the other stakeholders and may go a long way in explaining the gap between research and policy (Hermans, 2005).

\section{Choose whom and what to serve}

The next rule that we propose is that researchers should consciously choose which stakeholders and which interests they want to serve. As argued in Sect. 2, research always reflects different interests and world views. In practice, therefore, researchers always make choices. Many of these choices are, however, made implicitly, and we propose that researchers reflect on the choices they make and make them more consciously.

Many researchers may not be comfortable with the idea of having to choose and may prefer to remain neutral. This may be one of the major reasons why many researchers prefer fundamental research. Yet, even fundamental research is not completely neutral. Sooner or later, fundamental research may lead to practical applications, but not everyone has the necessary knowledge to apply fundamental research or the necessary funds to hire others to do this for them.

Two further options are conducting research for government and conducting research for all stakeholders. Research for government usually means research for a sectoral government body, such as a department or an agency. This choice is relatively easy to justify if government functions democratically and if the government body involved does not ignore the legitimate views and interests of other stakeholders. In other cases, research for government may reinforce an unjust social system or simply remain ineffective because of opposition from influential stakeholders that have not been involved. Research for all stakeholders seems a universally right choice, but it is not always possible in practice. If the number of stakeholders is large, one has to work with representatives that do not necessarily represent all interests or represent them equally well. In addition, there may be good reasons for excluding some groups of stakeholders, such as illegal abstractors or warlords. Besides, research for all stakeholders implies no research for any stakeholder in particular, such as an oppressed minority.

Researchers are not completely free to choose the stakeholders and the interests they want to serve. Their options depend on the broader social, political and institutional context and, more specifically, on the policy of their research organization and the funding possibilities. Moreover, their choices are influenced by their disciplinary bias and personal worldview (see also Sect. 2). It is impossible to see one's own bias directly - the eye cannot see itself -, but researchers may become aware of their own bias if they have an open mind and actively seek different approaches and points of view.

\section{Decide on your strategy}

Researchers may serve stakeholders and interests in different ways. First of all, they may aim for different types of research use (cf. Neilson, 2001). Many aim for so-called "instrumental use": use of research to resolve a specific issue, e.g. whether to build a hydropower dam or not. However, much research is not used in this way. Research may for instance show that a proposed hydropower dam will result in significant erosion downstream, but the dam may still be built because it is the policy of the Ministry of Water Resources to promote hydropower construction. Nonetheless, the research may have shed new light on the issue of hydropower and in the longer run may result in fundamental policy innovation, e.g. in more attention for energy saving. This type of research use is called "conceptual use" and is in fact more common than instrumental use (Weiss, 1977; Amara et al., 2004).

Researchers and their clients may also aim for "strategic use". Strategic use occurs when research is used exclusively 
to legitimize preferred solutions and further particular agendas. An example is Margaret Thatcher's appropriation of climate change in 1988 in order to dismantle the coal industry and promote nuclear power (Carvalho and Burgess, 2005). To facilitate strategic use, some alternatives or effects may be excluded from consideration, specific assumptions may be used and conclusions may be formulated in a specific way (e.g. a new technology may be called "promising" instead of "untested" or "risky"). Other stakeholders may then conduct or order research that studies different alternatives and effects, uses different assumptions, and arrives at different conclusions. Possibilities for counter expertise in themselves are not bad because all research includes subjective elements (cf. Sect. 2) and counter expertise may help to discover and discuss these, but if a real "report war" ensues (cf. Buuren and Edelenbos, 2004), stakeholders may close themselves off to alternative information, research is reduced to a weapon, and scientific quality may be impaired.

Different types of intended research use entail different types of relationships with the stakeholders. Researchers may, for instance, opt for advocacy research and support a specific client or promote a specific cause, such as nature conservation. This calls for close collaboration with the stakeholder or stakeholders concerned and often implies confrontation with other stakeholders (cf. Busenberg, 1999, "adversarial analysis").

Researchers may also facilitate learning and decisionmaking by the whole network of stakeholders (cf. Busenberg, 1999, "collaborative research"). They may try to cater to the information needs of all stakeholders and help them to clarify the issues and structure their discussions (Craps and Maurel, 2003). Facilitative research can potentially lead to a common factual basis for management, but, like all facilitation, it is not completely neutral. The researcher has to decide whether he wants to facilitate a specific network of stakeholders or not and his interventions will inevitably influence the process and the outcome.

In addition, researchers may work in isolation from the other stakeholders. This strategy gives researchers complete freedom to develop innovative concepts and approaches that may run counter to current policy and to public opinion. There is, however, a real danger that researchers following this strategy unwittingly end up selling their subjective preferences in terms of objective research, for instance because they use concepts that imply value judgements (cf. Box 2). Researchers should, as a minimum, be explicit about the choices they make and how they make them and discuss their own values (Douglas, 2005). This requires a lot of selfreflection.

\section{Design the process to implement your strategy}

Research strategies can be implemented in different ways. It often helps to make a detailed process design, specifying what will be done by whom, when and how. It is, however, important to maintain as much flexibility as possible in order to be able to respond adequately to new developments (Monnikhof, 2006). Major changes require the consent of the stakeholders involved in the research in order to minimize the risk of losing support and commitment (Ridder et al., 2005).

The specific research activities depend on the research strategy that is chosen. Quite often, the starting point for researchers is a specific tool or method that they are familiar with and believe to provide a solution for many problems (cf. Hermans, 2005). A better approach in theory is to first identify and analyze the issues at stake and then select the tool or method that can address these issues most effectively. In practice, however, most researchers master only one or a few tools. What they could do is to develop a clear view on the possibilities as well as the limitations of their tools, assess the needs in the specific case, and become involved only when their tools are appropriate.

A large number of tools and methods are available for supporting collaborative processes, such as participatory modelling and group model building, consensus conferences, focus groups, citizen juries, public hearings and science shops (Funtowicz and Ravetz, 1990; Vennix, 1999; Ubbels and Verhallen, 2000; Backstrand, 2003; Douglas, 2005; Ridder et al., 2005). Generally, collaboration works best if it starts early and if researchers and the other stakeholders determine the research needs together (Raadgever and Mostert, 2007). In practice, however, the other stakeholders are often involved only after the researchers have specified the research. This may reduce the relevance of the research for the other stakeholders and can reduce their willingness to participate and the acceptance of the results. Similar problems may occur if researchers collaborate with one or a few stakeholders only or if they work with representatives who do not represent their group or organization correctly (for instance only one or two high-level civil servants to represent a large international basin, as happened at some project meetings in the NeWater project).

\section{Communicate!}

Communication plays a key role in all research strategies. It is central to collaborative research because there can be no collaboration without communication, but it is equally important in non-collaborative research, albeit in a different way. Non-collaborative research usually applies the "public understanding of science" or PUS model, also known as the deficiency model or the scientific literacy model. This model is based on the assumption that there is a need for the stakeholders to understand particular scientific concepts and facts and that the experts should teach them these concepts and facts. The concepts and facts themselves are portrayed as fixed and certain (see for an example Stamm et al., 2000). 


\begin{abstract}
Over the past three decades, a large body of literature on communicating "risk" has developed. The traditional expert approach has been to define risk in terms of the probability of an adverse event and the consequences of this event (e.g. Jonkman et al., 2002; Bruijn, 2004a, b; Gouldby and Samuels, 2005). This has been called the "objective risk" and has been contrasted with the subjective risk perceptions by the members of the public (Clarke and Short, 1993). The main task for risk communication in this approach is to educate the public about the objective risks. However, the public often does not accept the risk assessments made by the experts.

Different reasons have been given for the risk communication problems, such as the communication skills of the experts and the issue of trust (this section). In addition, the risk assessments made by the expert may reflect different values than those of the public (cf. Sjoberg, 2002; Douglas, 2005; cf. section 2). This is even true for something as basic as the risk indicators used (cf. Fischhoff et al., 1984). Flood risks, for example, may be expressed in terms of individual risk - the individual probability of drowning per year - or in terms of collective risks the average number of casualties in a specific area per year. Whereas the first option favours equal flood protection for all, the latter favours a higher level of flood protection in densely populated areas and lower level in sparely populated areas.

A fundamental cause of risk communication problems is the different risk concept used. Technical experts usually distinguish between risk assessment on the one hand, and risk acceptability and risk management on the other. Lay persons, however, do not make this distinction and use a more holistic risk concept. Their risk assessments include factors such as trust in risk management, their own degree of control, vulnerability to the risk, the voluntary or involuntary character of the risk, their attitude towards the risky activity or situation, and the benefits they derive from this activity or situation (e.g. Slovic, 1999; Sjöberg, 2000). Without a proper dialogue between the risk experts and the public, there is a high probability that the assessment by the experts is not relevant for the public and is not accepted by them.
\end{abstract}

Box 2. Communicating "risk".

Despite many efforts applying the PUS model, there is little evidence of any increase in public understanding of science (Logan, 2001; Weigold, 2001; Kim, 2007). This is often attributed to the inability of the experts to communicate clearly and to the limited intellectual capacities and background knowledge of the other stakeholders and their limited willingness to learn. There is some truth in this. Many experts have difficulties speaking plain language and lack a clear view of their target audience and its interests and background knowledge. The policy brief on adaptation to climate change that was produced in the NeWater project provides just one example of ineffective communication (www.newater.info). This policy brief states for instance that: "A general global pattern is that the observed higher temperatures stimulate the global hydrological cycle, as more evapotranspiration leads to more water vapour content in the atmosphere and hence to higher precipitation amounts." (The brief then continues to discuss regional variations.) We may assume that the brief targets policy makers, such as politicians and their policy advisors, but these groups usually have limited hydrological knowledge and do not know what the "global hydrological cycle" or "evapotranspiration" is, nor will the research paper style of the sentence and of the policy brief as a whole appeal to them. A more effective sentence might have been: "If temperatures rise, more water will evaporate and rainfall will increase." 
In many cases, researchers could benefit from involving professional communication experts, but this may not prevent all problems. Increasingly, "trust" in the researchers and their research is mentioned as a crucial factor in science communication. As Brian Wynne $(1992,1996)$ pointed out, trust is not something that the public possesses or not: it results from the interactions between the researchers and their public and the social and institutional context (cf. Kramer, 1999; Bachman, 2001; Vangen and Huxham, 2003). Factors influencing trust include the track record of the researchers (have they been proven wrong in the past?), their consideration of the information and views of the public, their openness to criticism, their institutional affiliation, and the "recognizability" or relevance of their research. Recognizability does not only depend on the language that is used, but also on the concepts that are used and the values that are reflected in the research (cf. Sect. 2 and Box 2). Moreover, trust is influenced by the reputation of the models and methods used.

In reaction to the poor performance of the PUS model, an alternative model has been developed, called the contextual or interactive model (Logan, 2001; Weigold, 2001; Kim, 2007). Its starting point is not science, but the needs and interests of the public and the context in which they have to or can use the science. This model acknowledges the subjective or "constructed" character of science and pays as much attention to the production as to the consumption of knowledge. Communication in this view is not one-way transfer of knowledge from researchers to the other stakeholders, but a continuous interaction between these two groups.

Researchers using an isolation strategy necessarily have to rely on one-way communication, but also in more collaborative strategies many instances of one-way communication may occur. Researchers can interact directly with only a limited number of people, and to reach more they have to rely on books and reports, the mass media, word of mouth dissemination, and intermediaries such as communication officers of research institutes and journalists (Weigold, 2001).

\section{Consider your possibilities and limitations}

The final rule for researchers discussed in this paper is to consider your own possibilities and limitations. These include personal motivation and skills, disciplinary bias (Sect. 4) and institutional constraints. Collaborative research, for instance, requires good social skills, flexibility, and the ability to cope with complexity and ambiguity. Researchers who prefer to work on difficult but well-defined problems may be better suited for fundamental research using an isolation strategy.

The institutional constraints that researchers face include the reward structure in science and the research policy of funding agencies. The academic world generally rewards publications in journals with a high impact factor, usually mono-disciplinary journals that report about fundamental research. Popularization of science is often frowned upon
(Jacobson et al., 2004; Boer et al., 2006). Funding agencies, on the other hand, increasingly demand that research be "policy relevant" and addresses officially recognized issues and alternatives. The relative importance of these constraints depends on the type of research organization - governmental, commercial or academic - and more specifically on the organization's career policy. Researchers facing both types of constraints may try to sell their research ideas in terms of policy relevance, yet in practice pursue their scientific interests. Alternatively, they may redefine their concept of science and conduct action research for and with different stakeholders.

Not only researchers, but also the other stakeholders face constraints. For instance, an individual policymaker may want to avoid a "report war", but he or she may be forced to react when someone else starts such a war. Moreover, constraints are not given once and for all. Individuals may follow training, develop new interests, gain new experiences and increase their skills. Scientific journals may review their publication policy and research organizations their personnel policy. Moreover, organizations and inter-organizational networks may evaluate and change how they function. This is, however, quite difficult (cf. Argyris and Schön, 1996).

\section{Conclusions}

The aim of this paper was to stimulate reflection by researchers on their role in the policy process. To this end, we formulated seven rules for researchers. These rules do not constitute a recipe for success and leave room for different types of research. Each situation requires a different solution, depending on the stakeholders and issues at stake, current knowledge concerning the issues at stake, and the possibilities and limitations of the researchers.

In many cases, collaborative research will be the best option. First of all, this may be more democratic. If it is true, as we argued in section 2, that research always reflects values, it becomes especially important to involve the major stakeholders that may be affected. Moreover, collaborative research can be very pragmatic. By catering to the needs of the different stakeholders, the chances that research is used are maximized. Finally, there are also purely scientific reasons for collaborative research. Compared to "pure" research, collaborative research offers far greater possibilities for interdisciplinary cooperation, and it is at the interface of different disciplines that scientific innovation often takes place.

In all cases, following the seven rules will increase the contribution that research can make to the policy process. This is what we claim, based on our literature study and our own experiences in a number of projects, but we recognize that there is a need for more research. First, we recommend detailed case studies to assess whether in specific cases the rules were followed and what the contribution to the policy process has been. Interesting cases include cases where all 
rules seem to have been followed, but it is not clear what the contribution has been, and cases where the contribution has been big, but it is not clear whether the seven rules were followed. Secondly, survey research can be conducted using a more formal methodology and treating "compliance" with the different rules as independent variables and the contribution to the policy process as the dependent variable. However, this would require that indicators for compliance and the contribution to the policy process be developed first, which would be an interesting exercise in itself. For practical reasons, survey research would probably have to limit itself to one or a few rules and to one or a few possible impacts on the policy process. Thirdly, action research can be undertaken in which the researchers apply the rules themselves, observe the impact and reflect on the experiences gained. This may then lead new insights, to new applications, to new observations, to more reflection, etc. (cf. Kolb's experiential learning cycle: Kolb, 1984). Each research approach has advantages and disadvantages, potentials and risks. As with research in general, the best approach in a specific case will depend on the specifics of that case and on the possibilities and limitations of the researchers concerned.

To conclude, we still need to address one potential objection to our paper. If, as our paper argues, all research is subjective, if all research involves selection and interpretation and if the selection and interpretation made in a specific case reflect the values and preferences of those involved, where does this leave our paper? Is our paper not subjective? We think it is. Our paper reflects our personal interest in open, non-technocratic but well-informed decision-making, as well as our institutional affiliation - policy analysts in a water management department with a majority of hydrologists and engineers -, which compels us to reflect on the link between the policy process and technical and hydrological research. Yet, we think that our paper also reflects the reality of the (water) science - policy interface, that our analysis is valid and does not contradict the available data, and moreover, that it can be used by researchers who want to contribute to the policy process. It is up to the reader to check whether we are right, to test the validity of our analysis, to reflect on their own values and preferences, and if necessary, come up with an alternative analysis.

Acknowledgements. Earlier versions of this paper were presented at the Thursday Colloquium of the Water Resources Department of the Delft University of Technology (Delft, 7 June 2007), at the Workshop - Expert consultation on Low Flows and Drought, of the Commission for the Hydrology of the Rhine (Würzburg, Germany, 25 and 26 September 2007), and at the EGU General Assembly (Vienna, Austria, 13-18 April 2008). The authors would like to thank the participants at these three meetings for their comments and suggestions. Moreover, we would like to thank S. Junier (TU Delft) for commenting on an earlier version of this paper.

Edited by: P. van der Zaag

\section{References}

Allan, J. A.: Virtual water - the water, food, and trade nexus; useful concept or misleading metaphor?, Water Int., 28, 4-11, 2003.

Amara, N., Ouimet, M., and Landry, R.: New evidence on instrumental, conceptual, and symbolic utilization of university research in government agencies, Sci. Commun., 26, 75-106, 2004.

Argyris, C. and Schön, D.: Organizational learning II. Theory, method and practice, Addison-Wesley, Reading, Massachusetts, 1996.

Bachman, R.: Trust, power and control in trans-organizational relations, Organ. Stud., 22, 337-365, 2001.

Backstrand, K.: Civic science for sustainability: Reframing the role of experts, policy-makers and citizens in environmental governance, Global Environ. Polit., 3, 24-41, 2003.

Beck, U.: Risk society : Towards a new modernity, Sage Publications, London, Newbury Park, Calif., 1992.

Boer, Y. d., Gier, A. d., Verschuur, M., and Wit, B. d.: Building bridges; researchers on their experiences with interdisciplinary research in The Netherlands, RMNO, KNAW, NWO, COS, 2006.

Borrowski, I. and Hare, M.: Exploring the gap between water managers and researchers: Difficulties of model-based tools to support practical water management, Water Resour. Manag., 21, 2007.

Bourdieu, P.: Science de la science et réflexivité: Cours du Collège de France, 2000-2001, Collection "Cours et travaux", Raisons d'agir, Paris, 2001.

Bruijn, K. M. d.: Resilience and flood risk management, Water Policy, 6, 53-66, 2004a.

Bruijn, K. M. d.: Resilience indicators for flood risk management systems of lowland rivers, Int. J. River Basin Manage., 2, 199210, 2004b.

Busenberg, G.: Collaborative and adversarial analysis in environmental policy, Policy Sci., 32, 1-11, 1999.

Buuren, A. v. and Edelenbos, J.: Conflicting knowledge, Sci. Public Policy, 31, 289-299, 2004.

Caplan, N.: The two-communities theory and knowledge utilization, Am. Behav. Sci., 22, 459-470, 1979.

Carvalho, A. and Burgess, J.: Cultural circuits of climate change in UK broadsheet newspapers, 1985-2003, Risk Anal., 25, 14571469, 2005.

Clarke, L. and Short, J.: Social organization and risk: Some current controversies, Annu. Rev. Sociol., 19, 375-399, 1993.

Collingridge, D. and Reeve, C.: Science speaks to power: The role of experts in policy making, St. Martin's Press, New York, 1986.

Collins, H., and Evans, R.: The third wave of science studies: Studies of expertise and experience, Soc. Stud. Sci., 32, 235-296, 2002.

Craps, M. and Maurel, P.: Social learning in river basin management; pool of questions Harmonicop wp2 reference document, COPS, Leuven, 2003.

Dewulf, A., Craps, M., Bouwen, R., Taillieu, T., and Pahl-Wostl, C.: Integrated management of natural resources: Dealing with ambiguous issues, multiple actors and diverging frames, Water Sci. Technol., 52, 115-124, 2005a.

Dewulf, A., Gray, B., Putnam, L., Aarts, N., Lewicki, R., Bouwen, R., and Woerkum, C. v.: Disentangling approaches to framing: Mapping the terrain, 18th IACM Conference, Seville, 12-15 June 2005, 2005b. 
Douglas, H.: Inserting the public into science, in: Democratization of expertise? Exploring novel forms of scientific advice in political decision-making, edited by: Maasen, S. and Weingart, P., Sociology of the sciences 24, Springer, Dordrecht, 153-169, 2005.

Feyerabend, P.: Against method, Rev. ed., Verso, London, New York, 1988.

Fischhoff, B., Watson, S., and Hope, C.: Defining risk, Policy Sci., 17, 123-139, 1984.

Frankena, F.: The emergent social role and political impact of the voluntary technical expert, Environ. Impact Asses., 8, 73-82, 1988.

Freeman, R. E.: Strategic management: A stakeholder approach, Pitman series in business and public policy, Pitman, Boston [Mass.], London, 1984.

Funtowicz, S. O. and Ravetz, J. R.: Uncertainty and quality in science for policy, Theory and decision library. Series a. Philosophy and methodology of the social sciences vol. 15, Kluwer, Dordrecht, 1990.

Gieryn, T.: Boundary-work and the demarcation of science from non-science: Strains and interests in professional ideologies of scientists, Am. Sociol. Rev., 48, 781-795, 1983.

Gouldby, B., and Samuels, P.: Language of risk, available at http: //www.floodsite.net/, 2005.

Gray, B.: Collaborating : Finding common ground for multiparty problems, 1st ed., Jossey-bass management series, Jossey-Bass, San Francisco, 1989.

Hermans, L. M.: Actor analysis for water resources management putting the promise into practice, Eburon Publishers, Delft, 2005.

Hoekstra, A. and Chapagain, A.: Water footprints of nations: Water use by people as a function of their consumption pattern, Water Resour. Manag., 21, 35-48, 2007.

Hoekstra, A. Y. and Chapagain, A. K.: Globalization of water: Sharing the planet's freshwater resources, Blackwell Pub., Malden, MA, 2008.

Irwin, A.: The politics of talk: Coming to terms with the "new" scientific governance, Soc. Stud. Sci., 36, 299-320, 2006.

Jacobson, N., Butterill, D., and Goering, P.: Organizational factors that influence university-based researchers' engagement in knowledge transfer activities, Sci. Commun., 25, 246-259, 2004.

Jasanoff, S.: The fifth branch: Science advisers as policymakers, Harvard University Press, Cambridge, Mass., 1990.

Jasanoff, S.: (no?) accounting for expertise, Sci. Public Policy, 30, 157-162, 2003

Kim, H.: Pep/is: A new model for communicative effectiveness of science, Sci. Commun., 28, 287-313, 2007.

Knorr Cetina, K.: Laboratory studies: The cultural approach, in: Handbook of science and technology studies, edited by: Jasanoff, S., Markle, G. E., Petersen, J. C., and Pinch, T., Sage Publications, Thousand Oaks, Calif., 140-166, 1995.

Kolb, D. A.: Experiential learning : Experience as the source of learning and development, Prentice-Hall, Englewood Cliffs, N. J., 1984.

Kramer, R. M.: Trust and distrust in organizations: Emerging perspectives, enduring questions, Annu. Rev. Psychol., 50, 569-598, 1999.

Latour, B.: Science in action: How to follow scientists and engineers through society, Harvard University Press, Cambridge, Mass., 1987.
Logan, R.: Science mass communication: Its conceptual history, Sci. Commun., 23, 135-163, 2001.

Lorenz, C. M.: Indicators for sustainable management of rivers, Vrije Universiteit, Amsterdam, 1999.

Monnikhof, R. A. H.: Policy analysis for participatory policy making, Delft University of Technology, Delft, 2006.

Mostert, E.: The challenge of public participation, Water Policy, 5, 179-197, 2003.

Mostert, E., Craps, M., and Pahl-Wostl, C.: Social learning: The key to integrated water resources management?, Water Int., in press, 2008.

Neilson, S.: Knowledge utilization and public policy processes: A literature review, IDCR, 2001.

Petts, J. and Brooks, C.: Expert conceptualisations of the role of lay knowledge in environmental decisionmaking: Challenges for deliberative democracy, Environ. Plann. A, 38, 1045-1059, 2006.

Pimentel, D., Harman, R., Pacenza, M., Pecarsky, J., and Pimentel, M.: Natural resources and an optimum human population, Popul. Environ., 15, 347-369, 1994.

Pinch, T. J. and Bijker, W.: The social construction of facts and artefacts: Or how the sociology of science and the sociology of technology might benefit each other, Soc. Stud. Sci., 14, 399441, 1984.

Plato and Lee, D.: The republic, Penguin classics, Penguin, Harmondsworth, 1974.

Raadgever, G. T. and Mostert, E.: The role of expert knowledge in collaborative water management, International Conference on Adaptive and Integrative Water Management (CAIWA), Basel, 12-15 November 2007, 2007.

Raadgever, G. T., Mostert, E., and van de Giesen, N. C.: Measuring perspectives on future flood management on the Rhine: Application and discussion of Q methodology, Hydrol. Earth Syst. Sci Discuss., 5, 437-474, 2008, http://www.hydrol-earth-syst-sci-discuss.net/5/437/2008/.

Ridder, D., E. Mostert, E., and Wolters, H. A. (Eds.): Learning Together To Manage Together; Improving Participation in Water Management, USF University of Osnabrueck, Osnabrueck, 2005.

Rip, A.: In a third wave of science studies?, Soc. Stud. Sci., 33, 419-434, 2003.

Scheer, S.: Communication between irrigation engineers and farmers; the case of project design in North Senegal, Wageningen University, Wageningen, 1996.

Sjoberg, L.: The allegedly simple structure of experts' risk perception: An urban legend in risk research, Sci. Technol. Hum. Val., 27, 443-459, 2002.

Sjöberg, L.: Factors in risk perception, Risk Anal., 20, 1-11, 2000.

Slovic, P.: Trust, emotion, sex, politics, and science: Surveying the risk-assessment battlefield, Risk Anal., 19, 689-701, 1999.

Stamm, K., Clark, F., and Eblacas, P.: Mass communication and public understanding of environmental problems: The case of global warming, Public Underst. Sci., 9, 219-237, 2000.

Thompson, M., Ellis, R., and Wildavsky, A. B.: Cultural theory, Political cultures, Westview Press, Boulder, CO, 1990.

Ubbels, A. and Verhallen, J. M.: Suitability of decision support systems for collaborative planning processes in water resources management, Riza-rapport 99.067, RIZA, Lelystad, 2000.

Vangen, S., and Huxham, C.: Nurturing collaborative relations; building trust in interorganizational collaboration, J. Appl. Be- 
hav. Sci., 39, 5-31, 2003.

Veeren, R. J. H. M. v. d.: Economic analyses of nutrient abatement policies in the rhine basin, Vrije Universiteit, Amsterdam, 2002.

Vennix, J.: Group model-building: Tackling messy problems, Syst. Dynam. Rev., 15, 379-401, 1999.

Watson-Verran, H. and Turnbull, D.: Science and other indigenous knowledge systems, in: Handbook of science and technology studies, edited by: Jasanoff, S., Markle, G. E., Petersen, J. C., and Pinch, T., Sage Publications, Thousand Oaks, Calif., 115139, 1995.

Weigold, M. F.: Communicating science: A review of the literature, Sci. Commun., 23, 164-193, 2001.
Weiss, C.: Research for policy's sake: The enlightment function of social research, Policy Anal., 3, 531-545, 1977.

Wichelns, D.: The role of 'virtual water' in efforts to achieve food security and other national goals, with an example from Egypt, Agr. Water Manage., 49, 131-151, 2001.

Wynne, B.: Misunderstood misunderstanding: Social identities and public uptake of science, Public Underst. Sci., 1, 281-304, 1992.

Wynne, B.: Misunderstood misunderstandings: Social identities and public uptake of science, in: Misunderstanding science? : The public reconstruction of science and technology, edited by: Irwin, A., and Wynne, B., Cambridge University Press, Cambridge; New York, 19-46, 1996. 